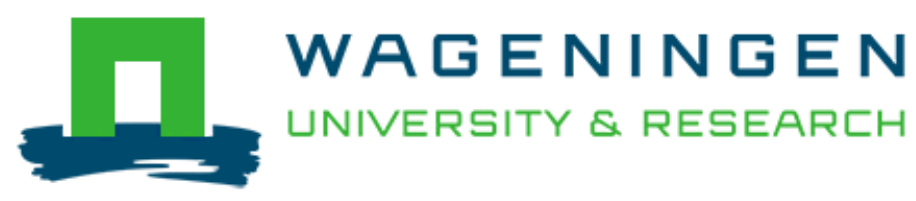

\title{
Deterministic displacement of particles and oil droplets in a cross-flow microsieve module
}

Dijkshoorn, J. P., Wagterveld, R. M., Boom, R. M., \& Schutyser, M. A. I.

This is a "Post-Print" accepted manuscript, which has been published in "Journal of Membrane Science"

This version is distributed under a non-commercial no derivatives Creative Commons

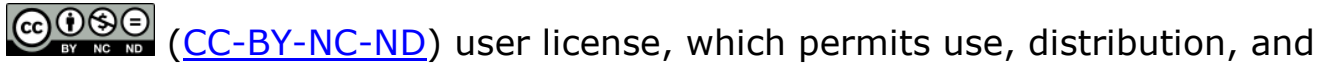
reproduction in any medium, provided the original work is properly cited and not used for commercial purposes. Further, the restriction applies that if you remix, transform, or build upon the material, you may not distribute the modified material.

Please cite this publication as follows:

Dijkshoorn, J. P., Wagterveld, R. M., Boom, R. M., \& Schutyser, M. A. I. (2018). Deterministic displacement of particles and oil droplets in a cross-flow microsieve module. Journal of Membrane Science, 566, 435-441. DOI:

10.1016/j.memsci.2018.08.065

You can download the published version at:

https://doi.org/10.1016/j.memsci.2018.08.065 


\section{Deterministic displacement of particles and oil droplets in a cross-flow}

\section{2 microsieve module}

3 J.P. Dijkshoorn ${ }^{\mathrm{ab}}$, R.M. Wagterveld ${ }^{\mathrm{b}}$, R.M. Boom ${ }^{\mathrm{a}}$, M.A.I. Schutyser ${ }^{\mathrm{a}}$

\footnotetext{
a Laboratory of Food Process Engineering, Wageningen University, Bornse Weilanden 9, 6708WG, Wageningen, The Netherlands

${ }^{\mathrm{b}}$ Wetsus, European Centre of Excellence for Sustainable Water Technology, Oostergoweg 9, 8911MA, Leeuwarden, The Netherlands

*Corresponding author: Maarten.Schutyser@wur.nl
}

Key words: Oil-water separation, Cross-flow microfiltration, Microsieve, Microfluidics, Deterministic lateral displacement

\section{Abstract}

Our investigation aims to apply Deterministic Lateral Displacement (DLD) to separate (deformable) particles or droplets from dispersions on industrial scale. DLD is a promising technique because it can separate particles smaller than the pores. Previous work shows how to manipulate the critical particle diameter in a sieve-based lateral displacement system by modifying the hydrodynamics. In this study, we apply this fundamental understanding of the DLD separation principle to deterministically displace particles in a cross-flow microsieve module. First, two-dimensional simulations of the fluid dynamics in this cross-flow module were performed to investigate the hydrodynamic conditions required for particle displacement. Next, these simulations were compared with the flow fields visualized in the experimental setup. In addition, high speed recordings confirmed deterministic displacement of particles and oil droplets over the microsieve surface. Last, the systems performance was evaluated by measuring the transmission of rigid PMMA particles and deformable hexadecane droplets and the particle size distribution for different operation conditions. These results clearly demonstrate that the DLD principle can be effectively applied in a cross-flow microsieve module. With this, the application of this microfluidic separation principle to separate particles or droplets (1 to 20 micrometer) from dispersions on industrial scale has become realistic. 


\section{Introduction}

Separation of dispersed particles is important in many sectors: for example in medical laboratories, in water treatment plants or in the food industry. While dispersions of particles that are larger than $20 \mu \mathrm{m}$ are generally separated with centrifuges or decanters, this is more difficult with smaller particles, especially when the particles are near neutrally buoyant and/or easily deformed [1-3]. One cannot use gravity based techniques for these dispersions (e.g. centrifugation) or (micro)filtration, because the particles block the pores or deform and pass the membrane pores [4].

This study focuses on deterministic lateral displacement (DLD) system, which uses tilted obstacle arrays to separate particles smaller than the gaps or pores between the pillars $[5,6]$. To be separated, particles require to have a radius larger than the width of the stream that is about to flow into the next pore (Figure 1). These streams are called flow lanes. When the radii of the particles are larger than the width of the flow lanes, particle-obstacle interactions will displace these particles laterally and push their centre of mass just outside the flow lanes. Because particles are physically excluded from the flow lanes, they cannot be dragged into the gaps or pores and are guided laterally by the obstacle columns. These larger particles are laterally displaced and can be collected at the end of the obstacle column on one side of the system.

Application of the DLD separation principle has especially potential in biotechnological and food industries because process streams often contain deformable and neutrally buoyant particles. The DLD technology was evaluated as promising to separate such dispersions on larger scale [7-11]. While the DLD principle was discovered in a microfluidic device, the volumetric throughput of a single device has been increased to scale this microfluidic separation principle towards larger applications $[2,12,13]$. It was shown that particles can be displaced by particle-obstacle interactions without using the classical DLD obstacle arrays, but instead applying simplified sparse obstacle arrays [14]. These sparse lateral displacement designs are constructed with only a small number of rows of obstacles, which could be translated in a configuration of a set of parallel sieves that were placed at a small angle to the flow direction $[14,15]$. Particle displacement could be achieved by adjusting the hydrodynamic conditions to obtain flow lanes with a specific width in the sieve-based lateral displacement (SLD) design (Figure 
1B) $[16,17]$. The flow should be laminar and such that the axial velocity of the fluid just above the pores $\left(\mathrm{V}_{\mathrm{y}}\right)$ is larger but in balance with the transversal flow velocity into the pores $\left(\mathrm{V}_{\mathrm{x}}\right)$. If both flows $\left(\mathrm{V}_{\mathrm{y}}\right.$ and $\mathrm{V}_{\mathrm{x}}$ ) are controlled well, the width of the stream that flows into a pore can be defined (Figure 1). Preferably, the flow lanes and thus the critical particle diameter, have the same size along the length of the microsieve [17]. If all flow lanes are of equal size, a clear critical diameter defines whether a particle is displaced or not. In other words, to deterministically displace particles with the same diameter in the entire system, the hydrodynamic conditions $\left(\mathrm{V}_{\mathrm{y}} / \mathrm{V}_{\mathrm{x}}\right)$ must be balanced.

The influence of hydrodynamic conditions on displacement of suspended particles has been previously described when for example studying particle screening during shear flow across a wall with suction via side branch channels [18]. In this study the phenomenon of particle displacement or particle screening was subscribed to the deviation of the particle trajectory from the fluid streamlines of the fluid entering the side branch channel because of interaction with the pore entrance. This is slightly different from the fluid skimming mechanism that removes the particle-free layer [19]. Moreover, it appeared that the ratio of the magnitudes of the cross and the shear flows influenced the screened particle size. In yet another microfluidic study it was observed that if specific hydrodynamic conditions are applied during suspension flow in a system with side channels, a portion of fluid near the wall is withdrawn from the main stream into the side stream [20]. These conditions could be adjusted such that particles whose diameter is larger than a critical value would not enter the side channels, even if a particle is located close to the wall and it is smaller than the cross section of the side channel [20]. Both Wu et al. and Yamada et al. describe very similar conditions that prevent particles from entering a side channel, like also was described for SLD technology [17]. However, these two examples focus on controlling individual side streams for a single pore, which can be placed in series. Only Van Dinther et al. employed a similar principle to facilitate higher throughputs [21]. They investigated cross-flow microfiltration with balanced cross-flow and permeate flow to enable particle separation in dilute suspensions [21]. Yeast cells $(\sim 5 \mu \mathrm{m})$ were successfully separated from a dilute suspension using a microsieve with pores of $20 \mu \mathrm{m}$. While successful separation was achieved, the operation of the device was not optimised. 
Based on our previous work and literature, we formulate a new hypothesis that particle displacement does not require a distinct DLD design (e.g. angle, size of the gaps or obstacle size) but can be achieved by control of the hydrodynamic conditions $[17,18,20,21]$. More specifically, by controlling the ratio of the axial and transversal velocities $\left(\mathrm{V}_{\mathrm{y}} / \mathrm{V}_{\mathrm{x}}\right)$, it is possible to separate particles with the DLD principle in unconventional DLD designs (Figure 1BC), such as a cross-flow microsieve module, in which the microsieve is not placed in an angle with respect to the flow direction (Figure 1).
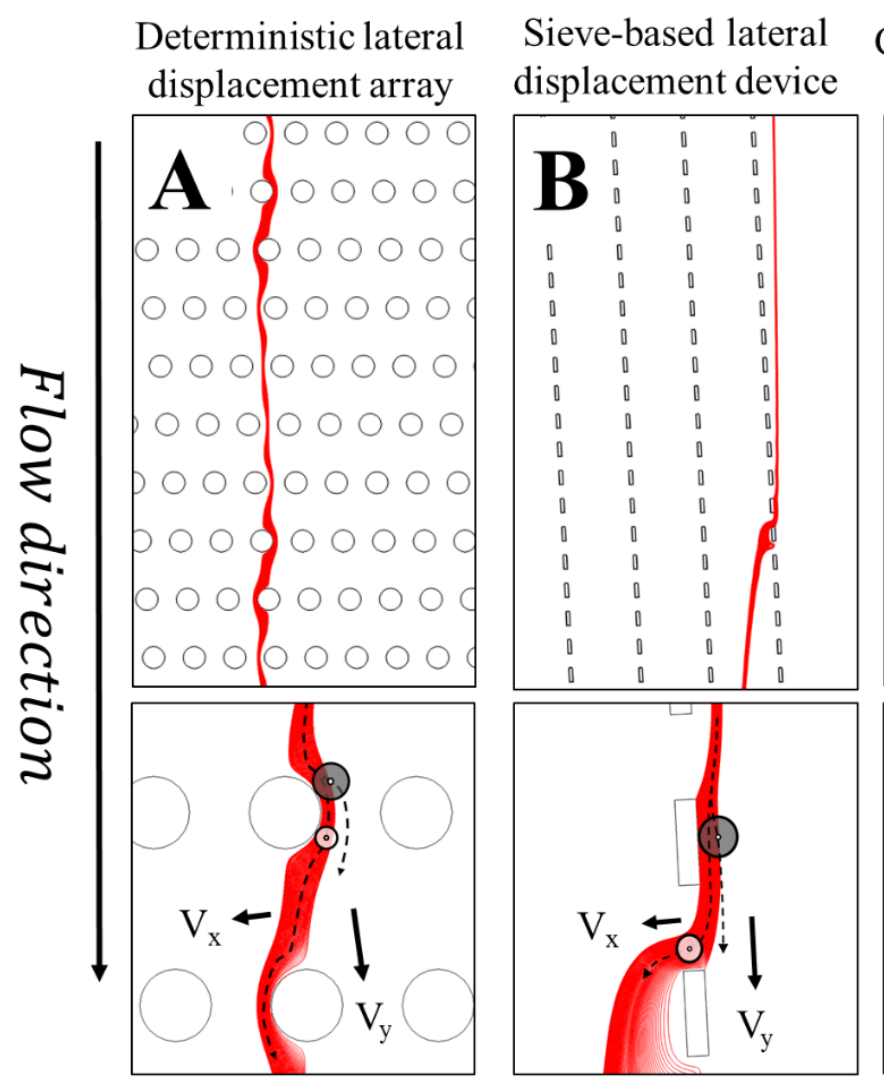

\section{Cross-flow microsieve}
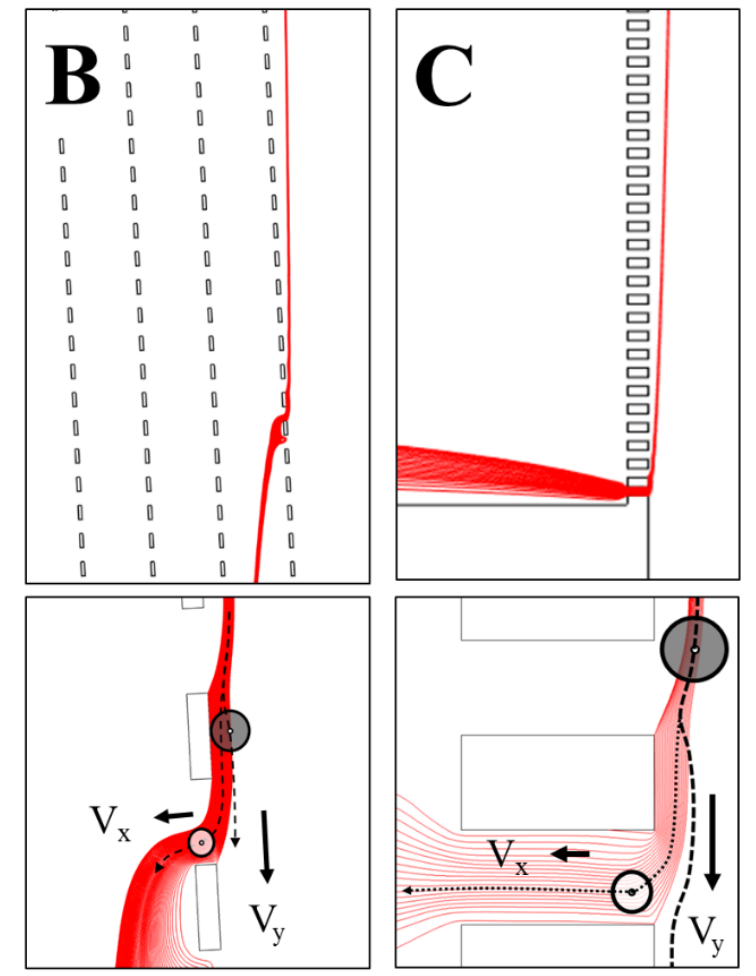

Figure 1: Three geometries with flow lanes (red) are shown that allow deterministic displacement of particles. In (A) the original deterministic lateral displacement (DLD) array, in (B) a sieve-based lateral displacement (SLD) device and in (C) a cross-flow microsieve (CFM) module. In the close-up figures the flow lanes and separation principle is illustrated for each system. Particles with a radius larger than the flow lanes (grey) are physically excluded from the flow lane by particle-structure interactions, the smaller particles (white) cannot be physically excluded and are dragged into the pore by the flow lane. The width flow lane can be changed by influencing the velocity components $\left(\mathrm{V}_{\mathrm{y}}\right.$ and $\left.\mathrm{V}_{\mathrm{x}}\right)$.

This study therefore aims at resolving the local hydrodynamics in a cross-flow microsieve device and subsequently use this to displace (deformable) particles that are smaller than the pores. Firstly, numerical simulations of the fluid dynamics in this cross-flow module were performed to investigate the 
hydrodynamic conditions required for particle displacement. Afterwards, these simulations were compared with the flow fields visualized by high speed recordings in the experimental setup. In addition, we recorded and confirmed deterministic displacement of particles and oil droplets $(25 \pm 5 \mu \mathrm{m})$ over the microsieve surface (supplementary videos). Lastly, the systems performance was evaluated by measuring the transmission of rigid PMMA particles and deformable hexadecane droplets (Stokes number $<<1$ if the particles are in the proximity of the microsieve) and the particle size distribution for a cross-flow velocity of $0.6 \mathrm{~m} / \mathrm{s}(\sim 1 \mathrm{~L} / \mathrm{min}$ and $\sim \operatorname{Re}: 2400)$ with varying permeate flow velocities $0.4-$ $7.9 \mathrm{~mm} / \mathrm{s}(2-50 \mathrm{~mL} / \mathrm{min})$.

\section{Results and discussion}

\section{Numerical simulation of deterministic displacement in the cross-flow module}

A cross-flow microsieve (CFM) module was numerically simulated in 2D, with COMSOL 5.3 [22]. A range of inlet and outlet flow velocities was simulated to find the best balance between the velocity of the feed flow across the microsieve $\left(\mathrm{V}_{\mathrm{y}}\right)$ and the velocity of the fluid flowing through pores of $50 \mu \mathrm{m}$ $\left(\mathrm{V}_{\mathrm{x}}\right)[17]$

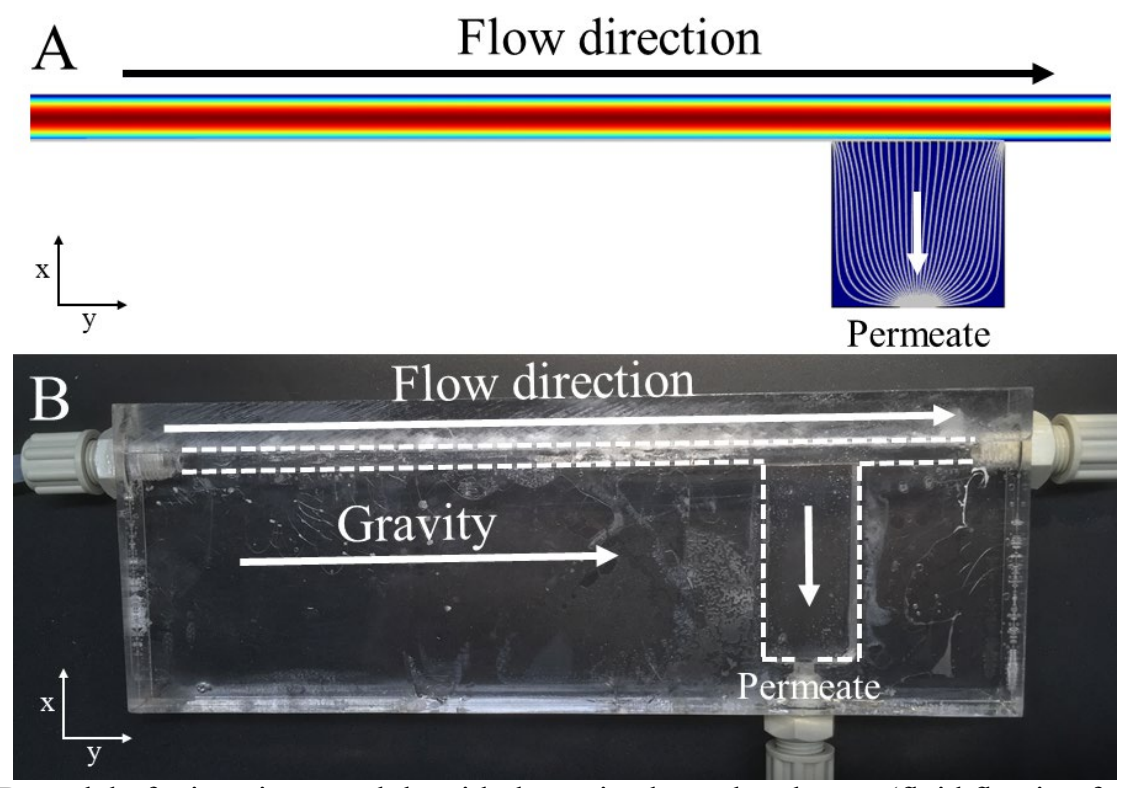

Figure 2: (A) 2D model of microsieve module with the main channel at the top (fluid flowing from left to right), and a side channel with in between a microsieve. The colour indicates the velocity magnitude (from red to blue indicates from high to low) and the stream lines are shown in grey. (B) The cross flow microsieve module used for the experiments (white dotted lines are drawn to guide the eye). The microsieve module was placed such that the flow direction was from top to bottom (y) and the permeate flow to the side (x). 
We show three different operating conditions and their influence on the $\mathrm{V}_{\mathrm{y}} / \mathrm{V}_{\mathrm{x}}$ ratio along the microsieve

(Figure 3): one where the permeate flow, relative to the cross flow, is too low (B); one where the permeate flow and cross flow velocity are in balance $(\mathrm{C})$; and one where the permeate flow relative to the cross flow is too high (D). If the permeate flow is low, the $V_{y} / V_{x}$ ratio becomes negative at the end of the channel: the direction of the flow reverses and fluid flows back into the main channel (Figure $3 \mathrm{AB})$. This happens when the pressure drop in the main channel is larger than the pressure drop over the microsieve and limits the length of a single microsieve. In the situation that the permeate flow (and pressure difference over them membrane) is too high, $\mathrm{V}_{\mathrm{y}} / \mathrm{V}_{\mathrm{x}}$ decreases across the length of the sieve (Figure $3 \mathrm{AD}$ ); as a result the flow lanes gradually become larger and particles may no longer be separated (Figure 4). For separation, one should therefore balance the cross-flow velocity $\left(\mathrm{V}_{\mathrm{y}}\right)$ with the velocity of the fluid flowing through the pores $\left(\mathrm{V}_{\mathrm{x}}\right)$ (Figure $\left.3 \mathrm{AC}\right)$. The size of the flow lanes for the three situations illustrated in Figure 3 are shown in Figure 4.
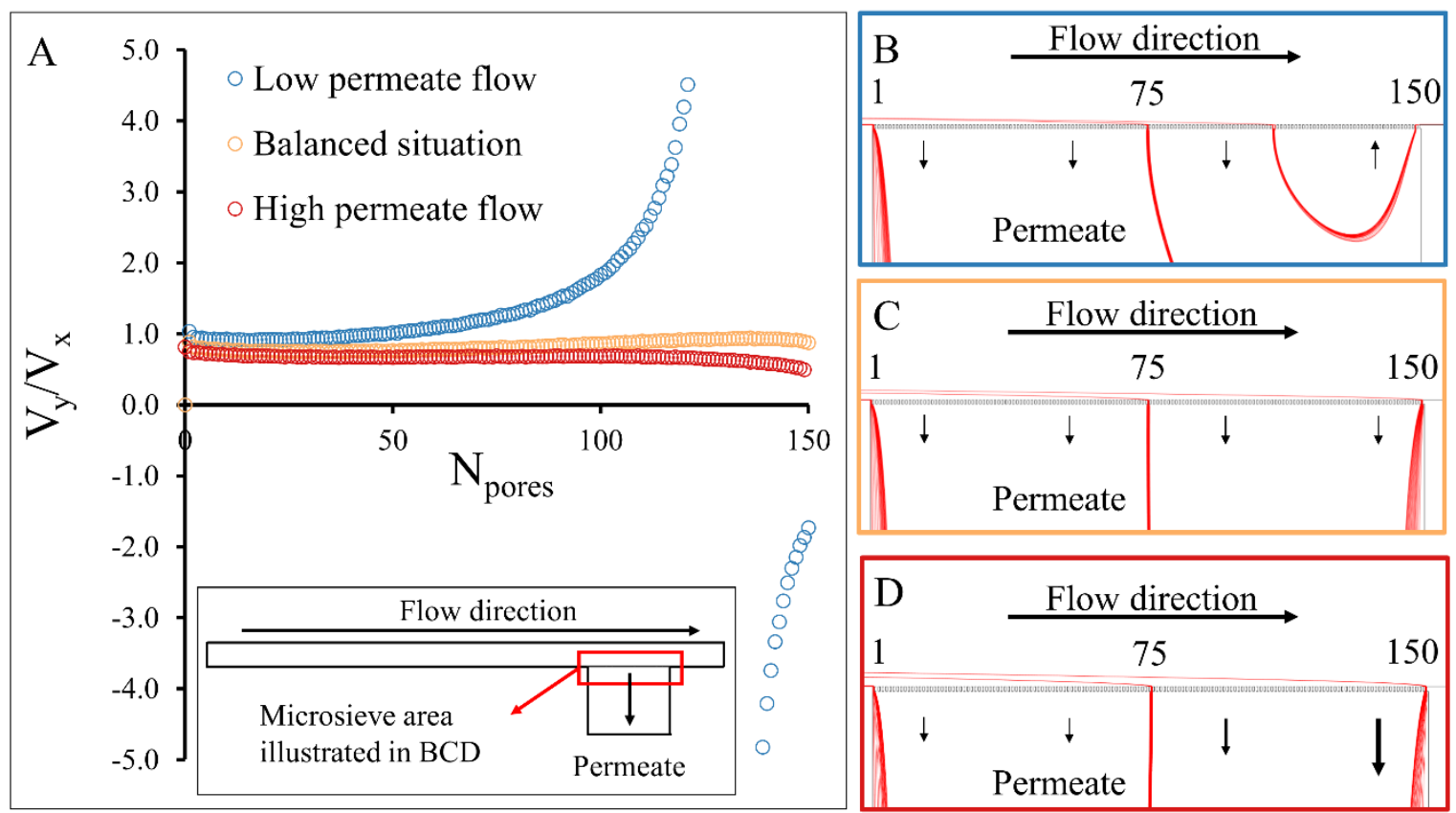

Figure 3: (A) The ratio between $V_{y}$ and $V_{x}$ (velocity on the boundary of the pores and main channel) for three different situations over the microsieve. (BCD) Flow lanes in red are shown in a cross-flow microsieve module (the location of BCD is indicated by the red box in A) with the feed fluid flowing from left to right over 150 pores, a microsieve in the middle and on the bottom the permeate. Three flow lanes (red) visualize the flow field for three situations with equal inlet flow velocity $(0.3 \mathrm{~m} / \mathrm{s})$ : (B) a low permeate flow velocity $(0.5 \mathrm{~mm} / \mathrm{s})$, (C) the balanced situation $(1.0 \mathrm{~mm} / \mathrm{s})$ and (D) a higher permeate flow $(1.3 \mathrm{~mm} / \mathrm{s})$.

114 These simulations suggest that it is possible to create uniform flow lanes within a cross-flow microsieve 115 module by adjusting the hydrodynamic conditions. Particles will be displaced when their radius is larger 
than the width of a flow lane implying that their centre of mass falls outside the flow lane. Because flow

117 lanes are smaller for lower permeate flows (Figure 4), these conditions can separate the smallest particles

118 (diameter of $\sim 30 \mu \mathrm{m}$ ), while the pores are $50 \mu \mathrm{m}$. However, the overall permeate flow is small and a

119 reversed flow is observed. A too high permeate flow relative to the cross-flow will increase the size of

120 the flow lanes (Figure 4) and therefore the critical particle diameter will also be larger $(\sim 60 \mu \mathrm{m})$. This

121 means that the only particles that are separated are particles larger than the pores $(50 \mu \mathrm{m})$ implying that

122 the separation is by conventional filtering. However, in the intermediate situation (Figure 4), when the

123 cross flow $\left(\mathrm{V}_{\mathrm{y}}\right)$ and the permeate flow $\left(\mathrm{V}_{\mathrm{x}}\right)$ are balanced, the flow lanes are of equal size $(17 \mu \mathrm{m})$ over

124 the entire sieve. This balanced situation can separate particles with a diameter of $\sim 34 \mu \mathrm{m}$, which is

125 smaller than the pore size $(50 \mu \mathrm{m})$.

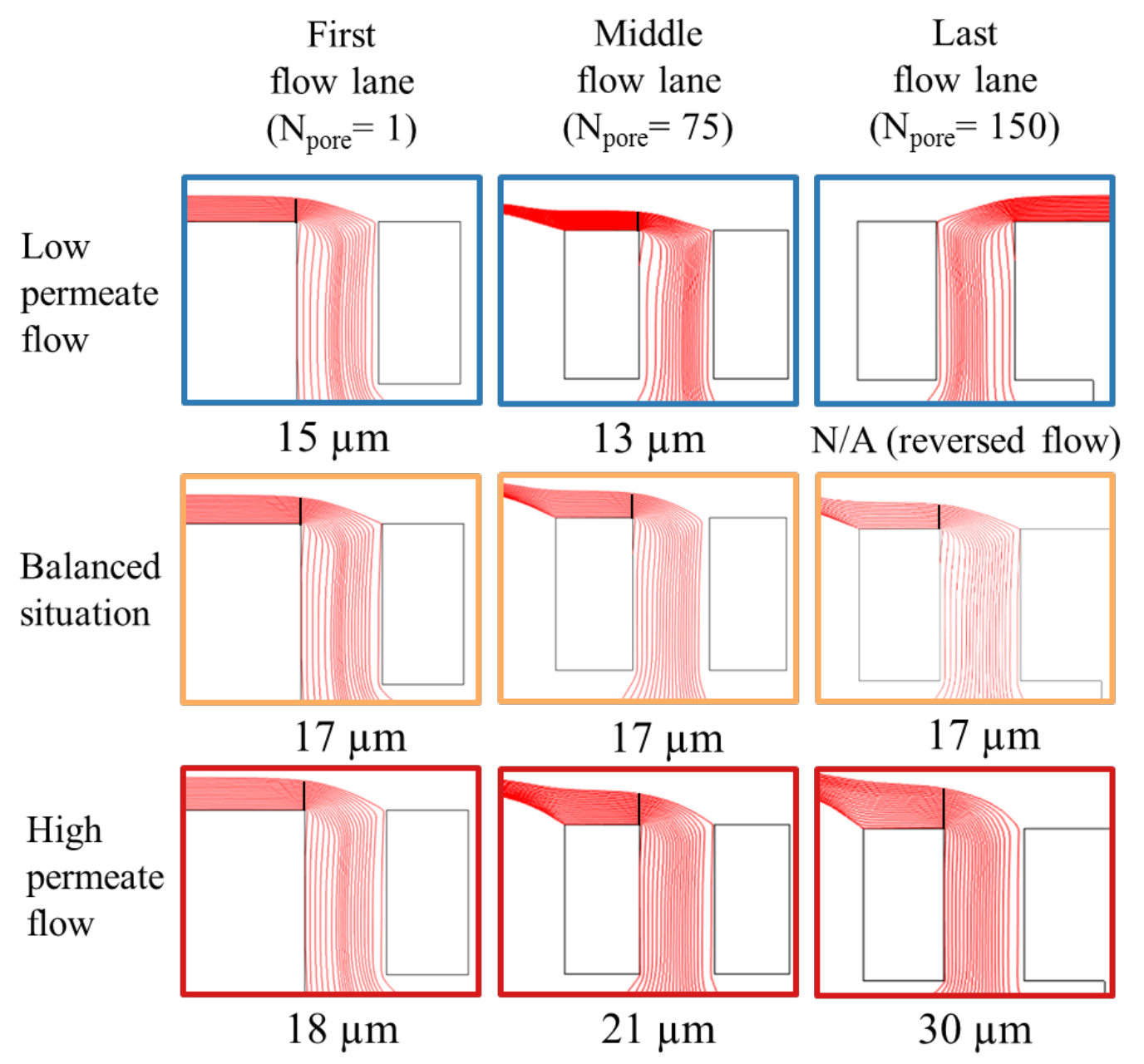

Figure 4: Flow lane width at the start $\left(\mathrm{N}_{\text {pore }}=1\right)$, in the middle $\left(\mathrm{N}_{\text {pore }}=75\right)$ and at the end $\left(\mathrm{N}_{\text {pore }}=150\right)$ of the microsieve for different operation conditions (Figure 3). Streamlines are shown in red and the thick black line indicates the width of the flow lane. The width of the pores is $50 \mu \mathrm{m}$. 
126 High speed imaging to visualize the flow field for model validation

127 A cross-flow module with a microsieve was constructed to validate the numerical simulations (Figure

128 2). Small tracer particles $(2 \mu \mathrm{m})$, that were not retained, were introduced and recorded to visualize the flow field. The system was operated with an average cross-flow velocity $\left(\bar{V}_{\mathrm{y}}\right)$ of $0.3 \mathrm{~m} / \mathrm{s}(500 \mathrm{ml} / \mathrm{min}$ and $\operatorname{Re}$ of $\sim 1200$ ) and three different average permeate flow velocities $\left(\bar{V}_{\mathrm{x}}\right)$. The experimental recordings of the high speed camera were superimposed to visualize the path lines of particles flowing through the

132 sieve, subsequently these were overlaid with the simulated streamlines (Figure 5). Similar to the

133 simulations, a reversed flow was observed with a permeate flow velocity of $\sim 0.6 \mathrm{~mm} / \mathrm{s}(4 \mathrm{ml} / \mathrm{min})$. The

134 reversed flow disappeared after increasing the permeate flow velocity to $\sim 1.1 \mathrm{~mm} / \mathrm{s}(7 \mathrm{ml} / \mathrm{min})$ and with

135 these conditions the cross-flow velocity and the permeate flow velocity appeared to be balanced. Further

136 increasing the permeate flow velocity to an extreme permeate flow velocity of $\sim 28.6 \mathrm{~mm} / \mathrm{s}(180 \mathrm{ml} / \mathrm{min})$

137 led to a situation with very large flow lanes which will drag particles that are smaller than the pores

138 through the microsieve. 

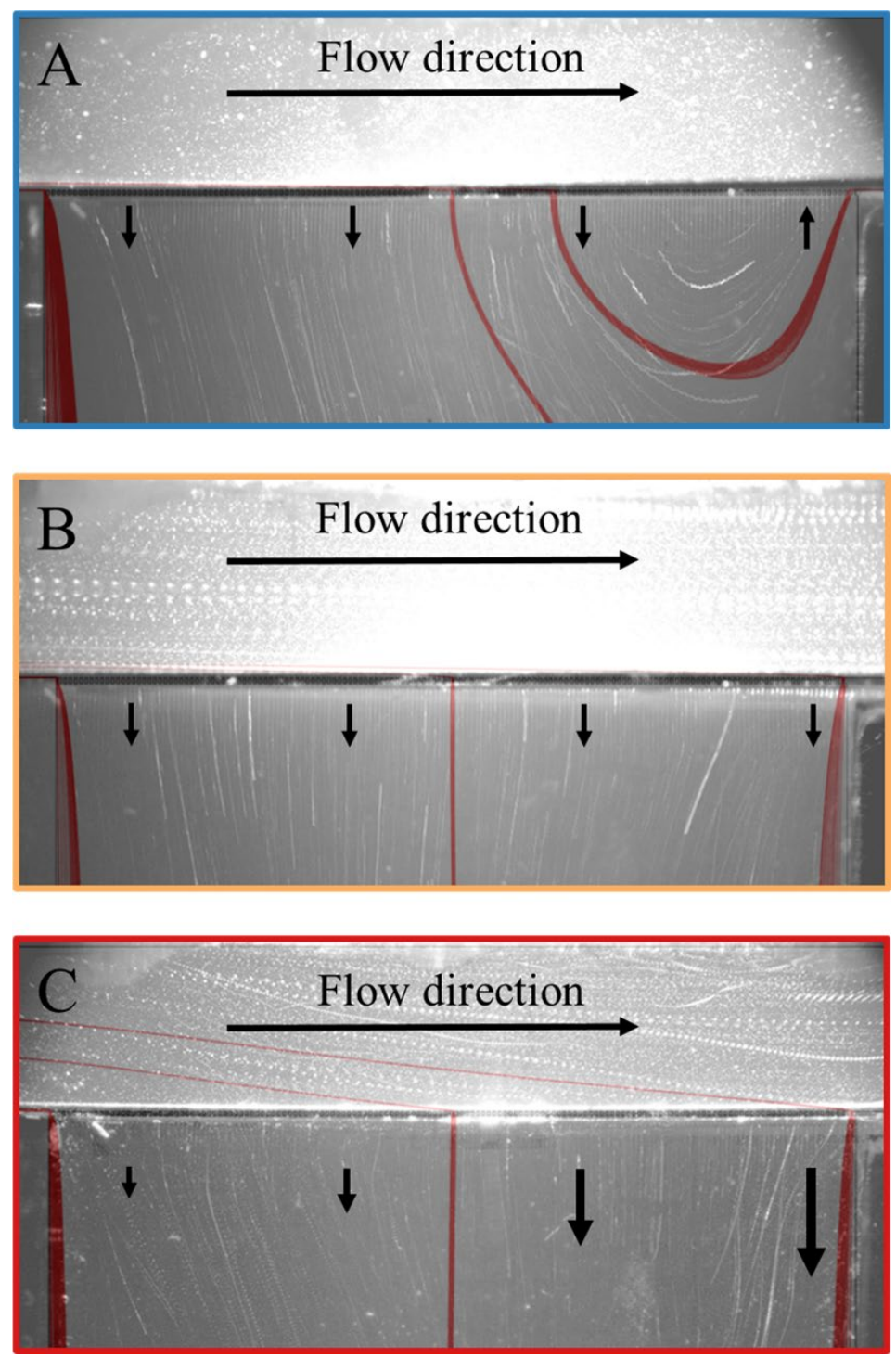

Figure 5: Experimental visualized flow field in CFM module with an average inlet flow velocity of $0.3 \mathrm{~m} / \mathrm{s}$ and three different average permeate flow velocities: (A) a low average permeate flow velocity $(\sim 0.6 \mathrm{~mm} / \mathrm{s}),(B)$ a balanced situation $(\sim 1.1 \mathrm{~mm} / \mathrm{s})$ and $(C)$ an extreme average permeate flow velocity $(\sim 28.6 \mathrm{~mm} / \mathrm{s})$.

140 The experimental pathlines were qualitatively similar to those simulated with the 2D model. Following

141 these results we established hydrodynamic conditions that would enable displacement of particles

142 targeted for separation, which are larger than the tracer particles but smaller than the pores in the

143 microsieve.

\section{Particle and droplet displacement in the cross-flow device}

145 Experiments were conducted to investigate to what extent particles that smaller than the pores can be

146 displaced in the module with varying conditions. Because we could not measure the local velocity

147 components $\left(\mathrm{V}_{\mathrm{y}}\right.$ and $\left.\mathrm{V}_{\mathrm{x}}\right)$ in the pores as in the numerical simulations, the experimental operation

148 conditions are described using the average cross-flow velocity $\left(\bar{V}_{\mathrm{y}}\right)$ in the channel and the average 
permeate flow velocity $\left(\bar{V}_{\mathrm{x}}\right)$ flowing through the microsieve. The experimental velocity ratio $\left(\bar{V}_{\mathrm{y}} / \bar{V}_{\mathrm{x}}\right)$

150 was, therefore, much higher than the local velocity ratio $\left(\mathrm{V}_{\mathrm{y}} / \mathrm{V}_{\mathrm{x}}\right)$ obtained from the numerical

151 simulations. The system was operated with an average cross-flow velocity of $0.6 \mathrm{~m} / \mathrm{s}(\sim 1000 \mathrm{ml} / \mathrm{min}$

152 and $\operatorname{Re}$ of $\sim 2400$, which is in the transition regime) and the average permeate flow velocity was varied

153 ranging between $0.4 \mathrm{~mm} / \mathrm{s}(\sim 2 \mathrm{ml} / \mathrm{min})$ and $7.9 \mathrm{~mm} / \mathrm{s}(\sim 50 \mathrm{ml} / \mathrm{min})$, which is equivalent to a permeate

154 flux of $1480 \mathrm{~L} / \mathrm{m}^{2} / \mathrm{h}$ and $22860 \mathrm{~L} / \mathrm{m}^{2} / \mathrm{h}$ with a transmembrane pressure of $15 \pm 5 \mathrm{mbar}$. The permeate flux

155 in the balanced situation was close to $4000 \mathrm{~L} / \mathrm{m}^{2} / \mathrm{h}$ (Figure 5). The fluxes applied in this study are of

156 similar magnitude compared to those used by others that used microsieves for cross-flow microfiltration

$157[21,23-25]$. However, the flux is several times higher compared to the fluxes reported in other studies

158 for conventional membrane microfiltration of oil-in-water emulsions $\left(50-1200 \mathrm{~L} / \mathrm{m}^{2} / \mathrm{h}\right)$ [26-28].

159 First, we performed concentration experiments using a model suspension of $0.1 \mathrm{v} / \mathrm{v} \%$ rigid PMMA

160 particles. Subsequently, we investigated the displacement of deformable hexadecane droplets in an oil-

161 in-water emulsion with different concentrations $(\sim 0.1 \mathrm{v} / \mathrm{v} \%, \sim 1 \mathrm{v} / \mathrm{v} \%$ and $\sim 5 \mathrm{v} / \mathrm{v} \%)$ (Figure 6$)$. The

162 transmission is a measure of the separation; it is the ratio of the concentration of particles or droplets in

163 the permeate over their concentration in the feed. The transmission is expected to vary with the flow

164 conditions described by the ratio between $\bar{V}_{\mathrm{y}} / \bar{V}_{\mathrm{x}}[21]$. The x-axis shows the applied velocity ratio and

165 the y-axis transmission. To highlight the regions of the three operational conditions (discussed above),

166 the graph is subdivided in three sections: a high permeate flow velocity (red), a balanced situation

167 (orange) and a low permeate flow velocity (blue) (Figure 6). A high permeate flow velocity would be

168 desired to make effective use of the total microsieve surface area, however particles will not be displaced

169 in that situation and transmit through the microsieve. Alternatively, a low transmission at low permeate

170 flow velocity would be desired for optimal recovery, but then the microsieve surface area is not used

171 effectively because the flow reverses near the end of the microsieve. The optimal condition for this

172 microsieve module is therefore the balanced flow situation where transmission and operation conditions

173 lead to high displacement at still reasonable permeate flux. 


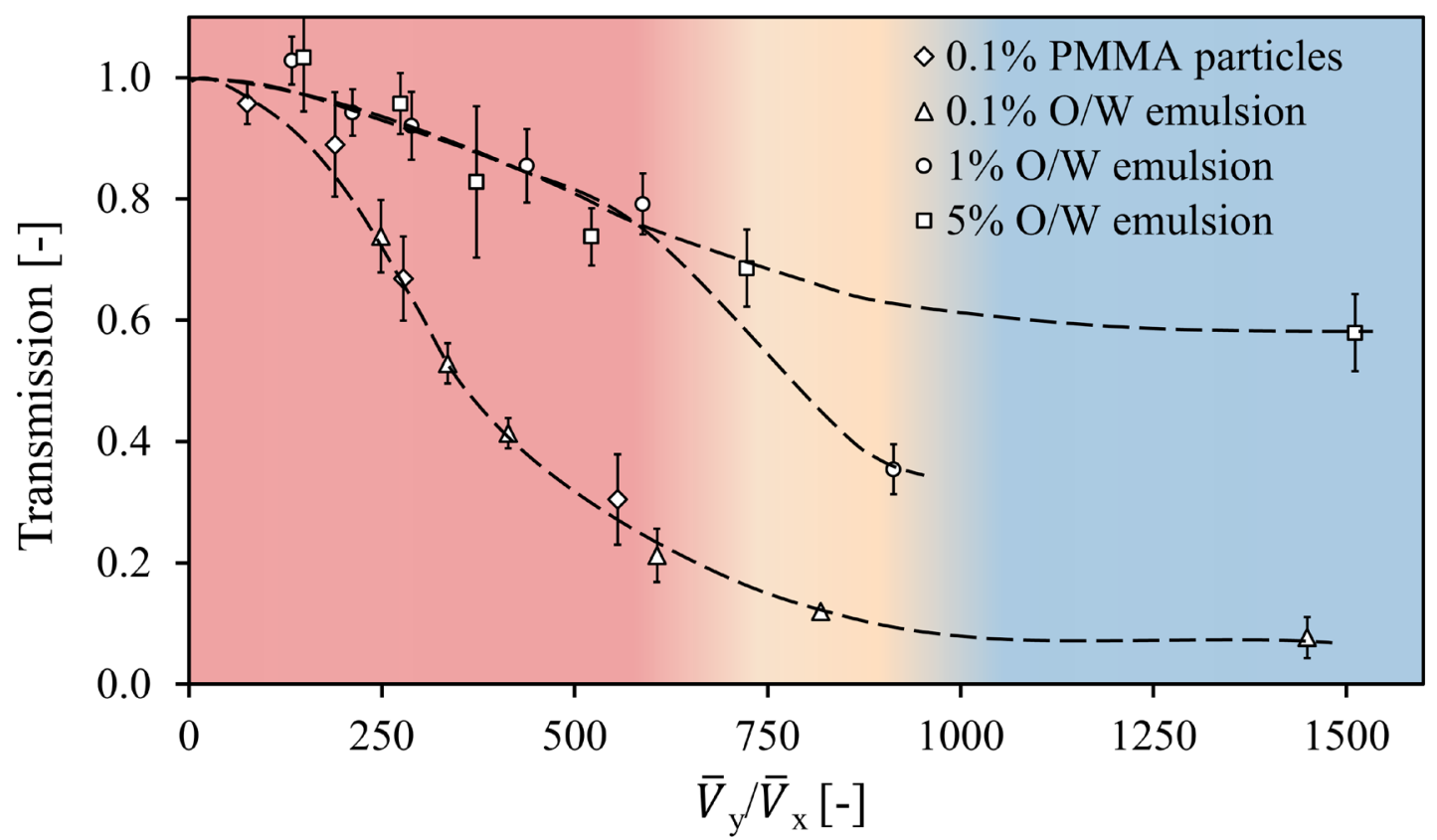

Figure 6: Displacement of PMMA particles and hexadecane oil droplets in water for three concentrations. The transmission decreases for an increasing velocity ratio $\left(\bar{V}_{\mathrm{y}} \bar{V}_{\mathrm{x}}\right)$. The red section indicates the region where $\bar{V}_{\mathrm{x}}$ is too high for particle displacement, the blue section indicates the region where $\bar{V}_{\mathrm{x}}$ is too low and reversed flow is observed. The orange region shows the situation where $\bar{V}_{y}$ and $\bar{V}_{\mathrm{x}}$ are balanced and particles or oil droplets are displaced using the DLD separation principle. The black dashed lines are drawn to guide the eye.

The transmission indeed decreases with an increasing velocity ratio $\left(\bar{V}_{\mathrm{y}} / \bar{V}_{\mathrm{x}}\right)$. The trend observed for the dispersions with concentration of $0.1 \mathrm{v} / \mathrm{v} \%$ is similar to the situation described by Dinther et al. [21], although with a different interpretation. The rigid PMMA particles behave quite similar to the hexadecane droplets and suggests that separation is not significantly influenced by possible deformation of the droplets at these low concentrations. The stresses exerted by the flow $(\mathrm{V}=0.1 \mathrm{~m} / \mathrm{s})$ on the hexadecane droplets $(\sigma=53.5 \mathrm{mN} / \mathrm{m}$ and $\mathrm{d}=25 \mu \mathrm{m})$ near the microsieve surface are insufficient to deform the droplets $\left(C a=\mu V / \sigma \ll 1\right.$ and $\left.W e=\rho V^{2} d / \sigma \ll 1\right)$. However, droplet-microsieve collisions can deform (flatten) the droplets and have a negative impact on separation. In the supplementary videos some deformation can be observed if looked at closely. The limited effect of deformability on separation that we observed is especially interesting for separation of applications with particles or droplets of 0.1 $\mu \mathrm{m}$ to $10 \mu \mathrm{m}$ that have a density close to that of the continuous phase, like many emulsions and cells or micro-algae suspensions. It should be noted that the data of the rigid PMMA particles are limited to low concentrations and low $\bar{V}_{\mathrm{y}} / \bar{V}_{\mathrm{x}}$ (red region); therefore, we are cautious with conclusions about the limited effect of deformability on separation. For higher concentrations (1v/v\% and $5 \mathrm{v} / \mathrm{v} \%)$ one can observe that separation is less effective and that the transmission declines at higher velocity ratio $\left(\bar{V}_{\mathrm{y}} / \bar{V}_{\mathrm{x}}\right)$ 

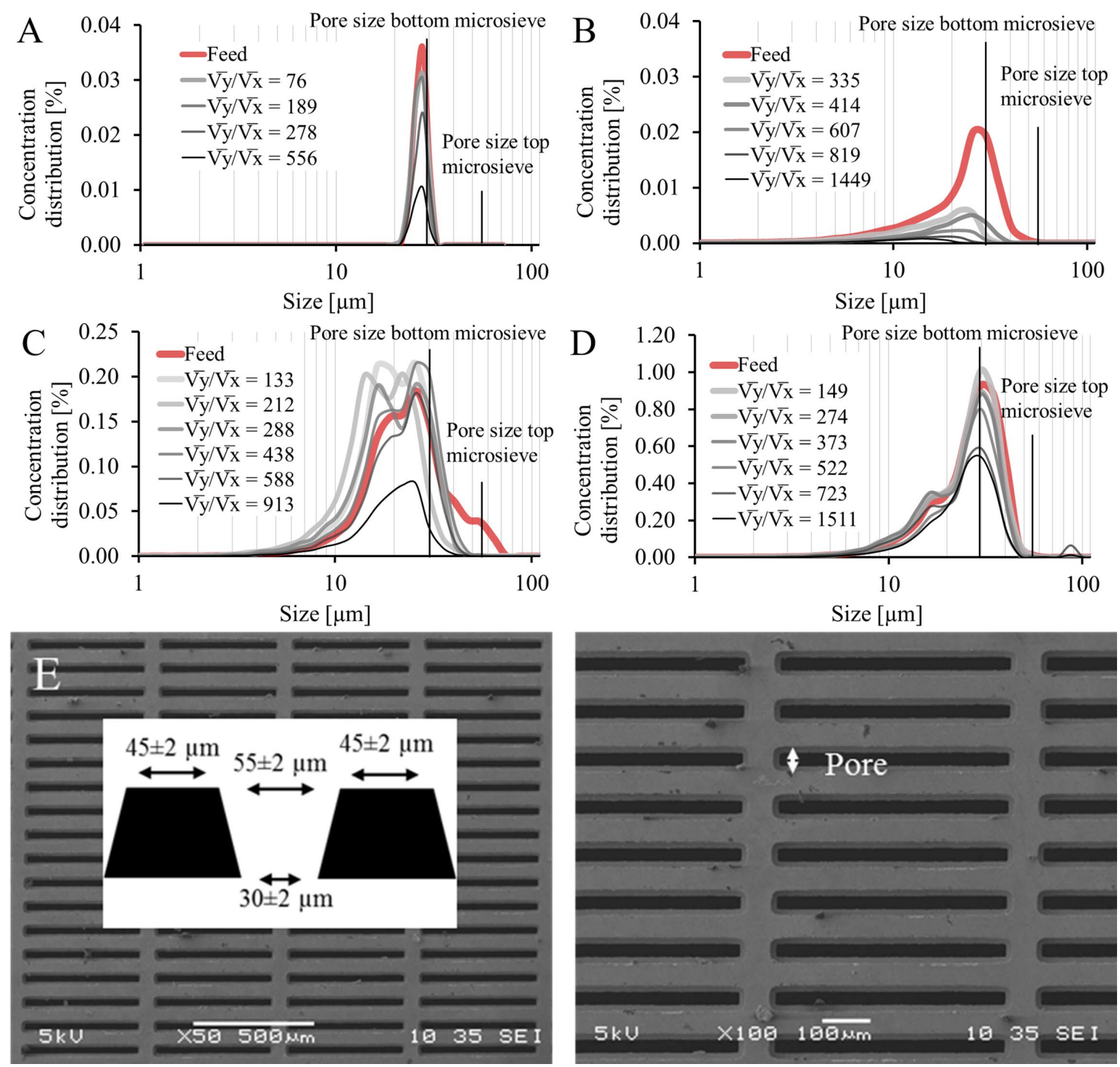

Figure 7: Particle concentration distribution of the permeate (Figure 6) with lines to indicate the size of the pores of the microsieve. The feed contained: (A) $0.1 \mathrm{v} / \mathrm{v} \%$ PMMA particles, (B) $0.1 \mathrm{v} / \mathrm{v} \%$ hexadecane, (C) 1 $\mathrm{v} / \mathrm{v} \%$ hexadecane and (D) $5 \mathrm{v} / \mathrm{v} \%$ hexadecane. (E) SEM images of a representative microsieve that was used in the experimental module with different magnification (x50 and x100). IMAGEJ was used to measure the size of the pores (top: $55 \pm 2 \mu \mathrm{m}$ by $500 \pm 5 \mu \mathrm{m}$ and bottom: $30 \pm 2 \mu \mathrm{m}$ by $475 \pm 5 \mu \mathrm{m}$ ).

Figure 7A shows the particle concentration distribution of the PMMA particles (feed concentration of

$1940.1 \mathrm{v} / \mathrm{v} \%$ ) and Figure 7BCD show the particle concentration distribution of the hexadecane droplets in

195 water, with a feed concentration of $0.1 \mathrm{v} / \mathrm{v} \%$ in $\mathrm{B}, 1 \mathrm{v} / \mathrm{v} \%$ in $\mathrm{C}$ and a concentration of $5 \mathrm{v} / \mathrm{v} \%$ in $\mathrm{D}$, for all the velocity ratios shown in Figure 6 . The reduction in transmission for a low feed concentration $(0.1$ 
$\mathrm{v} / \mathrm{v} \%$ ) shown in Figure 6 can also be observed in the concentration distribution (Figure 7AB). The concentration distribution decreases with increasing $\bar{V}_{\mathrm{y}} / \bar{V}_{\mathrm{x}}$ and Figure $7 \mathrm{~B}$ shows that the average particle size in the permeate becomes smaller. Figure 7CD illustrates the particle concentration distributions of the permeate stream for experiments with a feed concentration of $1 \mathrm{v} / \mathrm{v} \%$ and $5 \mathrm{v} / \mathrm{v} \%$. The concentration distributions in Figure 7CD do not shift towards smaller droplets as much as the lower concentration in Figure 7B; even though a minor shift can be observed for the highest $\bar{V}_{\mathrm{y}} / \bar{V}_{\mathrm{x}}$ values. Figure $7 \mathrm{BCD}$ underpins the results shown in Figure 6 that separation becomes less effective with increasing feed concentration. The influence of the feed concentration on the separation and particle concentration distribution can be a result of particle-particle interactions (in this case droplet-droplet interaction). The frequency of these interactions depends on the square of the concentration of the particles. However, presence of a concentrated layer of particles or droplets will affect the hydrodynamics in the system and influence the hydrodynamic balance and the flow lanes [29-31]. This can affect the hydrodynamic regions (the red, orange and blue sections) in which particles can be displaced and reduce the effectiveness of the separation principle.

Figure 7E shows scanning electron microscopic (SEM) images of the microsieves. The dimensions of the pores at the top surface of the microsieves were $55 \pm 2 \mu \mathrm{m}$ by $500 \pm 5 \mu \mathrm{m}$, but the dimensions of the pores at the bottom surface of the microsieves were $30 \pm 2 \mu \mathrm{m}$ by $475 \pm 5 \mu \mathrm{m}$, which is a consequence of the electroforming process. The influence of the tapered pore shape on the flow lanes was inspected using 2D numerical simulation. Minor effects were observed on the pressure drop across the membrane at the highest cross-flow velocities, which stabilized the pressure distribution along the microsieve and the flow lane size. The size of the pores at the bottom of the microsieves $(30 \mu \mathrm{m})$ does not affect separation because particle displacement only occurs at the top surface of the microsieve (supplementary videos). If a particle or droplet enters a pore they either get stuck in the pore or leave via the permeate flow. The smaller pore size at the bottom did not affect our results because it can be observed that for a low $\bar{V}_{\mathrm{y}} / \bar{V}_{\mathrm{x}}$ ratio (range where conventional sieving takes place), also droplets larger than $30 \mu \mathrm{m}$ were found in the permeate flow (Figure 7BCD). These oil droplets were exposed to enough stress for them to deform and pass the lower, narrower end of the pores. 
These results demonstrate that our hypothesis is correct; particle displacement does not require a distinct DLD design (e.g. angle, size of the gaps or obstacle size) but can be achieved by control of the hydrodynamic conditions, and can even be applied to existing separation techniques such as microfiltration. This proves the potential of the deterministic lateral displacement separation principle for dispersion separation on industrial scale.

\section{Conclusion}

230 Deterministic displacement of dispersions was successfully achieved in a cross-flow microsieve module that had pores larger than the diameter of the rigid particles or deformable oil droplets. It was shown that the separation depends on the ratio of crossflow to permeate velocities. This was simulated by varying operating conditions and verified with high speed imaging. Concentration experiments with particles and droplets showed successful separation at the appropriate operation conditions and the existence of an optimum range with acceptable permeate flux and particle displacement. With higher concentrations, the performance of the separation declines. Our results show that the deterministic displacement principle can be applied in cross-flow microsieve devices. This facilitates the design of a system that can use a microfluidic separation principle to process neutrally buoyant and deformable dispersions on an industrial scale with lower energy requirements.

\section{Materials and methods}

\section{D numerical simulations}

242 The NS-equation was solved for a complete 2D geometry similar to that of the constructed flat plate cross-flow microsieve module (Figure 2). The simulations were performed using the finite element method ( $2^{\text {nd }}$ order elements for velocity and $1^{\text {st }}$ order elements for pressure $)$ in COMSOL Multiphysics 5.3 [22]. The microsieve was $150 \mathrm{~mm}$ long and $100 \mu \mathrm{m}$ thick. The pores in the microsieve were $50 \mu \mathrm{m}$ wide, $100 \mu \mathrm{m}$ deep and the spacing between the pores was $50 \mu \mathrm{m}$. The simulated water flow (at 293.15 K) through the system was assumed to be laminar, incompressible and stationary. Three average inlet velocities were calculated: $\sim 0.3 \mathrm{~m} / \mathrm{s}, \sim 0.6 \mathrm{~m} / \mathrm{s}$ and $\sim 0.9 \mathrm{~m} / \mathrm{s}$. The permeate outlet was swept for multiple outflow velocities $\left(\bar{V}_{\mathrm{x}}\right)$ in relation to the cross-flow velocities $\left(\bar{V}_{\mathrm{y}}\right)$. The outlet in the main channel was 
pressure based. A no-slip wall condition was applied and the results were checked for mesh dependency (selected mesh had $\sim 125,000$ elements). The $\mathrm{V}_{\mathrm{y}}$ and the $\mathrm{V}_{\mathrm{x}}$ were integrated over a cutline in each pore and three flow lanes were manually measured at the transition of an obstacle and gap [17].

\section{Image recording}

A high speed camera (1024 x 1024 pixels, $20 \times 20 \mu \mathrm{m}^{2} /$ pixel, Photron, SA1.1) and a magnifying lens (OPTEM ZOOM 125 1-13x) were used to record the motion of red polystyrene tracer particles $(\mathrm{d}=2$ $\mu \mathrm{m}, \rho=1.05 \mathrm{~g} / \mathrm{cm}^{3}$, Microparticles $\mathrm{GmbH}$ ) in milliQ water with $0.1 \mathrm{wt} \%$ non-ionic surfactant (Triton X100, Sigma Aldrich 9284) to prevent particles from aggregating. The tracer particles were selected because they had a low particle stokes number, were small enough to not influence the flow and scattered enough light when illuminated with a thin $(0.4 \pm 0.1 \mathrm{~mm})$ laser sheet ( $808 \mathrm{~nm}$, Firefly, Oxford lasers) that was positioned in the middle of the membrane at a depth $(\mathrm{z})$ of $3.5 \mathrm{~mm}$. The desired magnification $(\mathrm{M})$, appropriate recording frequency and pulse length were chosen depending on the particle velocity. A magnification of $M=1$ was used to record the entire membrane, with the resolution of 1 pixel $=20 \mu \mathrm{m}$. Particle screening or displacement of PMMA particles and hexadecane oil in water emulsions were recorded on top of the microsieve (supplementary videos). For these more detailed videos that focused on the pores, a magnification of $\mathrm{M}=9$ was used with a resolution of 1 pixel $=2.3 \mu \mathrm{m}$. The recording frequency varied between $0.5-2 \mathrm{kHz}$ and the pulse duration between 2-20 $\mu$ s with a pulse power of 0.03 $0.30 \mathrm{~mJ} / \mathrm{pulse}$.

\section{Flow field visualization}

The pathlines were visualized by superimposing 200 consecutively recorded images. This new superimposed image only shows the maximum intensity of the all 200 images for each pixel position (z-stack, IMAGEJ 1.51S, NIH).

\section{Dispersion preparation}

273 The model suspension was prepared with MilliQ water, $0.1 \mathrm{wt} \%$ non-ionic surfactant (Triton X-100,

274 Sigma Aldrich 9284) and $0.1 \mathrm{v} / \mathrm{v} \%$ PMMA microspheres with an average diameter of $27 \mu \mathrm{m}$ (Cospheric,

275 USA). The density of these particles was around $1.2 \mathrm{~g} / \mathrm{ml}$. The $0.1 \mathrm{v} / \mathrm{v} \%$ oil in water emulsion was prepared with hexadecane (Sigma Aldrich 6703), $0.5 \mathrm{w} / \mathrm{v} \%$ BiPRO Whey Protein Isolate (Davisco 
Foods, USA) and MilliQ water and was homogenised at 8000 RPM for 15 minutes using an Ultra-turrax

278

279

280

281

282

283

284

285

286

287

288

289

290

291

292

293

294

295

296

297

298

299

300

301

302

digital T25 (IKA, USA). The $1 \mathrm{v} / \mathrm{v} \%$ and $5 \mathrm{v} / \mathrm{v} \%$ oil in water emulsions were prepared with hexadecane (Sigma Aldrich 6703), 1w/v\% BiPRO WPI (Davisco Foods, USA) and MilliQ water and was homogenised at 9000 RPM for 15 minutes using an Ultra-turrax digital T25 (IKA, USA). Particles and droplets in the proximity of the microsieve have a $R e_{p}=\rho V d^{2} / \mu H \ll 1$ and $S t k=\tau V / l \ll 1$. Here $\rho$ is the density of the fluid with a viscosity $\mu$ flowing at a velocity $\mathrm{V}, \mathrm{d}$ is the particle diameter and $\mathrm{H}$ is the channel height $(4 \mathrm{~mm})$. The relaxation time is depicted by $\tau$ and 1 is the length of a pore in flow direction $(50 \mu \mathrm{m})$. The particle size distributions used for the concentration distributions in Figure 7 were measured with the EyeTech particle size analyser (Ankersmid, The Netherlands).

\section{Experimental setup}

A cross-flow microsieve module was manufactured as is shown in Figure 2. The channels were milled into transparent Poly methyl methacrylate (PMMA) plate. The main channel was $150 \mathrm{~mm}$ (y) by $4 \mathrm{~mm}$ (x) by $7 \mathrm{~mm}(\mathrm{z}$ ) and the side channel was $15 \mathrm{~mm}$ (y) by $40 \mathrm{~mm}$ (x) by $7 \mathrm{~mm}$ (z) with a microsieve (Veco B.V., The Netherlands) in between. This sieve was $15 \mathrm{~mm}$ long, $7 \mathrm{~mm}$ wide and $0.05 \mathrm{~mm}$ thick and had pores of $55 \pm 2 \mu \mathrm{m}$ by $500 \pm 5 \mu \mathrm{m}$ placed with a spacing of $45 \pm 2 \mu \mathrm{m}$ from each other in all directions on the top side. The pores at the bottom, however, were smaller because of the production process; they were $30 \pm 2 \mu \mathrm{m}$ by $475 \pm 2 \mu \mathrm{m}$ with a spacing between the pores of $70 \pm 2 \mu \mathrm{m}$ in all directions. The dispersed system was collected in a collection vessel and pumped (Masterflex L/S, Cole Parmer, US) to a pressure vessel to dampen the pulsations. The suspension was continuously recirculated through the system at the selected volumetric flow rate until the flow stabilized. The permeate flow rate was controlled by a needle valve.

\section{Acknowledgements}

This work was performed in the cooperation framework of Wetsus, European Centre of Excellence for Sustainable Water Technology (www.wetsus.eu). Wetsus is co-funded by the Dutch Ministry of Economic Affairs and Ministry of Infrastructure and Environment, the Province of Fryslân, and the Northern Netherlands Provinces. The authors like to thank the participants of the research theme 
'Advanced Water Treatment' for the fruitful discussions and their financial support. The authors also

like to thank H. van der Kooi, E.B.A. Hinderink and M.N. Corstens for their help.

305

306

307

308

309

310

311

312

313

314

315

316

317

318

319

320

321

322

323

324

325

326

327

328

329

330

331

332

333

334

335

336

337

338

339

340

341

342

343

344

345

346

347

348

349

350

351

352

353

354

1. Wakeman, R.J., Selection of equipment for solid/liquid separation processes. Filtration \& Separation, 1995. 32(4): p. 337-341.

2. Schroën, K., A. van Dinther, and R. Stockmann, Particle migration in laminar shear fields: A new basis for large scale separation technology? Separation and Purification Technology, 2017. 174: p. 372-388.

3. Dijkshoorn, J.P., et al., A comparison of microfiltration and inertia-based microfluidics for large scale suspension separation. Separation and Purification Technology, 2017. 173: p. 8692.

4. Barros, A.I., et al., Harvesting techniques applied to microalgae: A review. Renewable and Sustainable Energy Reviews, 2015. 41: p. 1489-1500.

5. Huang, L.R., et al., Continuous Particle Separation Through Deterministic Lateral Displacement. Science, 2004. 304(5673): p. 987-990.

6. Inglis, D.W., et al., Critical particle size for fractionation by deterministic lateral displacement. Lab on a Chip, 2006. 6(5): p. 655-658.

7. Kulrattanarak, T., et al., Classification and evaluation of microfluidic devices for continuous suspension fractionation. Advances in Colloid and Interface Science, 2008. 142(1-2): p. 53-66.

8. Davis, J.A., et al., Deterministic hydrodynamics: Taking blood apart. Proceedings of the National Academy of Sciences, 2006. 103(40): p. 14779-14784.

9. Holm, S.H., et al., Separation of parasites from human blood using deterministic lateral displacement. Lab on a Chip, 2011. 11(7): p. 1326-1332.

10. Green, J.V., M. Radisic, and S.K. Murthy, Deterministic Lateral Displacement as a Means to Enrich Large Cells for Tissue Engineering. Analytical Chemistry, 2009. 81(21): p. 9178-9182.

11. Henry, E., et al., Sorting cells by their dynamical properties. Scientific Reports, 2016. 6: p. 34375.

12. Lubbersen, Y.S., M.A.I. Schutyser, and R.M. Boom, Suspension separation with deterministic ratchets at moderate Reynolds numbers. Chemical Engineering Science, 2012. 73: p. 314-320.

13. Lubbersen, Y.S., et al., Visualization of inertial flow in deterministic ratchets. Separation and Purification Technology, 2013. 109(0): p. 33-39.

14. Lubbersen, Y.S., et al., Particle suspension concentration with sparse obstacle arrays in a flow channel. Chemical Engineering and Processing: Process Intensification, 2015. 95: p. 90-97.

15. Dijkshoorn, J.P., et al., Sieve-based lateral displacement technology for suspension separation. Separation and Purification Technology, 2017. 175: p. 384-390.

16. Dijkshoorn, J.P., et al., Reducing the critical particle diameter in (highly) asymmetric sievebased lateral displacement devices. Scientific Reports, 2017. 7(1): p. 14162.

17. Dijkshoorn, J.P., et al., Visualizing the hydrodynamics in sieve-based lateral displacement systems. Scientific Reports, 2018. 8(1): p. 12861.

18. Wu, W.-Y., S. Weinbaum, and A. Acrivos, Shear flow over a wall with suction and its application to particle screening. Journal of Fluid Mechanics, 1992. 243: p. 489-518.

19. Yan, Z.-Y., A. Acrivos, and S. Weinbaum, Fluid skimming and particle entrainment into a small circular side pore. Journal of Fluid Mechanics, 1991. 229: p. 1-27.

20. Yamada, M. and M. Seki, Hydrodynamic filtration for on-chip particle concentration and classification utilizing microfluidics. Lab on a Chip, 2005. 5(11): p. 1233-1239.

21. van Dinther, A.M.C., C.G.P.H. Schroën, and R.M. Boom, High-flux membrane separation using fluid skimming dominated convective fluid flow. Journal of Membrane Science, 2011. 371(1-2): p. 20-27.

22. COMSOL, M., in v. 5.3, COMSOL AB: Stockholm, Sweden.

23. Kuiper, S., et al., Filtration of lager beer with microsieves: flux, permeate haze and in-line microscope observations. Journal of Membrane Science, 2002. 196(2): p. 159-170.

24. Brito-de la Fuente, E., et al., Microfiltration of whole milk with silicon microsieves: Effect of process variables. Chemical Engineering Research and Design, 2010. 88(5): p. 653-660. 
25. Warkiani, M.E., et al., A high-flux isopore micro-fabricated membrane for effective concentration and recovering of waterborne pathogens. Biomedical Microdevices, 2012. 14(4): p. 669-677.

26. He, Z., et al., The effect of permeate flux on membrane fouling during microfiltration of oily water. Journal of Membrane Science, 2017. 525: p. 25-34.

27. Tanudjaja, H.J., et al., Effect of cross-flow velocity, oil concentration and salinity on the critical flux of an oil-in-water emulsion in microfiltration. Journal of Membrane Science, 2017. 530: p. 11-19.

28. Ullah, A., et al., Microfiltration of deforming oil droplets on a slotted pore membrane and sustainable flux rates. Journal of Membrane Science, 2011. 382(1): p. 271-277.

29. Amini, H., et al., Intrinsic particle induced lateral transport in microchannels. PNAS, 2012. 109(29): p. 11593-11598.

30. Wang, Y., R. Mauri, and A. Acrivos, The transverse shear-induced liquid and particle tracer diffusivities of a dilute suspension of spheres undergoing a simple shear flow. Journal of Fluid Mechanics, 1996. 327: p. 255-272.

31. Rohatgi, A., Shear-Induced Diffusion in Dilute Suspensions, in Chemical and Biomolecular Engineering. 2012, University of Notre Dame. 